\title{
Çocukluk çağında çölyak hastalığı ve Helicobacter pylori gastritinin görülme sıklığı ile aralarındaki ilişki
}

The incidence of and relationship between celiac disease and Helicobacter pylori gastritis in childhood

(D) Ferah TUNCEL ${ }^{1}$, (D) Funda BOZKURT ${ }^{1}$, (D) Arzu GÜLSEREN², (D) Yusuf USTA²

Mersin Universitesi Tıp Fakültesi, ${ }^{1}$ Tıbbi Patoloji Anabilim Dalı, ${ }^{2}$ Çocuk Sağhlğı ve Hastalıları Anabilim Dall, Gastroenteroloji Bilim Dall, Mersin, Içel

Giriş ve Amaç: Mikrobiyal maruziyetin çölyak hastalık riskini etkileyebileceği, kronik gastrik enfeksiyonların sistemik immün yanıtları etkileyerek ince bağırsakta otoimmüniteyi tetikleyebileceği ileri sürülmektedir. Bu çalışmanın amacı merkezimizde incelenen çocukluk çağına ait biyopsilerde çölyak hastalığı ve Helicobacter pylori gastritinin görülme sıklı̆̆ının araştırılması ve olası ilișkinin belirlenmesidir. Gereç ve Yöntem: 01.07.2015 01.01.2018 tarihleri arasında merkezimizde incelenen ince bağırsak ve/ veya mide biyopsileri bulunan tüm çocuk hastalar çalışmaya alınmış, mide biyopsilerinde Helicobacter pylori gastritinin, duodenum biyopsilerinde çölyak hastalığının görülme sıklığı belirlenmiștir. Aynı zamanda mide ve ince bağırsak biyopsileri bulunan ve çölyak hastalığı tanısı alan olgularda, otoimmün gastrite de neden olan Helicobacter pylori'nin beraber görülme sıklı̆g saptanarak aralarındaki ilişki değerlendirilmiştir. Bulgular: Mide ve/veya duodenum biyopsisi bulunan toplam 494 olgu çalışma kapsamına alınmış ve 43 olguda sadece mide biyopsisi, 12 olguda sadece duodenum biyopsisi değerlendirilmiştir. Incelenen 482 mide biyopsisinin 162'sinde Helicobacter pylori (\%33.6), 451 duodenum biyopsisinin 37'sinde çölyak hastalığ (\%8.2) tespit edilmiştir. Çölyak tanısı alan 33 olgudan 11'inde (\%33.3) Helicobacter pylori gastriti saptanmış, çölyak tanısı bulunan 4 olgu da mide biyopsisi bulunmadiğından değerlendirilememiştir. Duodenum biyopsisi bulunan ve Helicobacter pylori gastriti tanısı almış 144 olgunun ise 11 'inde çölyak hastalığı tespit edilmiştir. Sonuç: Çalışmamızda normal popülasyondaki çölyak hastalı̆̆ı sıklığı ile Helicobacter pylori gastritli olgulardaki çölyak hastalığ sıklığı benzer oranlarda saptanmıştır. Ayrıca normal popülasyondaki Helicobacter pylori gastriti sıklı̆̆ı ile çölyak hastalarındaki Helicobacter pylori gastritinin görülme sıklığı arasında anlamlı bir fark bulunmamıştır. Elde edilen sonuçların olası nedenleri araştırılmıştır.

Anahtar kelimeler: Çölyak hastalığı, Helicobacter pylori, gastrit

\section{GIIRIS}

Çölyak hastalı̆̆ı genetik olarak duyarlı bireylerde ortaya çıkan T hücre aracılı bir enteropatidir (1). Yapılan bazı araştırmalarda hastalığın prevalansının 1000 çocukta 3-13 arasında olduğu tespit edilmiştir (2). Çölyak hastalığ kript hiperplazisi ve villöz atrofi ile ilişkili olarak intraepitelyal lenfositlerin sayısında bir artışa neden olup, ince bağırsak mukozasında hasar meydana getirir (3). Bu hastalı̆̆ın patogenezi iyi tanımlanmıs olmasına rağmen, artan prevalansı ince bağırsakta otoimmüniteyi tetikleyebilen bir takım çevresel risk faktörlerinin göz önüne alınmasına neden olmuştur (4). Helicobacter pylori (H. pylori) enfeksiyonu tüm dünyada en sik görülen
Background and Aims: Microbial exposure may affect the risk of celiac disease, and chronic gastric infections may induce autoimmunity in the small intestine by affecting systemic immune responses. The aim of this study was to determine the prevalence of celiac disease and Helicobacter pylori gastritis in childhood biopsies at our center and to examine relationship between them. Materials and Methods: All pediatric patients with small intestine and/or gastric biopsies examined at our center between July 1, 2015 and January 1, 2018 were included in the study. The incidence of Helicobacter pylori gastritis and celiac disease was determined in gastric biopsies and duodenal biopsies, respectively. In patients with gastric and small intestine biopsies who were diagnosed with celiac disease, the incidence of Helicobacter pylori causing autoimmune gastritis was determined and the relationship between them was evaluated. Results: A total of 494 patients with gastric and/or duodenal biopsy were included in the study, with gastric and duodenal biopsies evaluated in 43 and 12 cases, respectively. Helicobacter pylori gastritis and celiac disease were detected in 162 of 482 (33.6\%) gastric biopsies and 37 of 451 (8.2\%) duodenal biopsies, respectively. Helicobacter pylori gastritis was detected in 11 of 33 (33.3\%) patients with celiac disease. Four patients with celiac disease could not be evaluated due to unavailability of gastric biopsy. Celiac disease was detected in 11 of 144 (7.6\%) patients with duodenal biopsy and a diagnosis of Helicobacter pylori gastritis. Conclusion: In our study, the frequency of celiac disease in the normal population and in patients with Helicobacter pylori gastritis was found to be similar. Additionally, there was no significant difference between the incidences of Helicobacter pylori gastritis in the normal population versus the patients with celiac disease. Possible reasons for these results have been investigated.

Keywords: Celiac disease, Helicobacter pylori, gastritis

gastrointestinal enfeksiyondur ve kronik gastrit, gastrik ülser, duodenal ülser ve gastrik maligniteler gibi birçok hastalığın ana nedenidir (5). H. pylori enfeksiyonu ve çölyak hastalığ arasındaki ilişki iyi belirlenmemiştir. Çeşitli çalışmalarda çölyak hastalığında $H$. pylori enfeksiyonunun prevalansının yüksek olduğu bildirilirken (6-7), aralarında herhangi bir ilişkinin saptanmadığı çalışmalar da mevcuttur (8).

$\mathrm{Bu}$ çalışmada merkezimizde incelenen çocukluk çağına ait biyopsilerde çölyak hastalığı ve H. pylori gastiritinin görülme sıklığını tespit edip, aralarındaki ilişkiyi değerlendirdik.
İletişim: Ferah TUNCEL Mersin Üniversitesi Tıp Fakültesi, Tıbbi Patoloji AD, 34. Cad. Çiftlikköy Kampüsü 33343, Yenişehir-Mersin E-mail: ferahdaloglu@hotmail.com Geliş Tarihi: 25.01.2019 Kabul Tarihi: 11.04.2019

Not: Bu çalışma 26-29 Ekim 2018 tarihleri arasında Ankara'da düzenlenen 28. Ulusal Patoloji Kongresi'nde poster bildirisi olarak sunulmuştur. 


\section{GEREC ve YÖNTEM}

01.07.2015-01.01.2018 tarihleri arasinda merkezimizde değerlendirilen ince barsak ve/veya mide biyopsileri bulunan tüm çocuk hastalar çalışmaya alınmıştır. Mideden biyopsi alınan çocuk hastalarda $H$. pylori gastritinin, duodenum biyopsisi bulunan çocuk hastalarda ise çölyak hastalığının görülme sıklığı belirlenmiştir. Aynı zamanda hem mide, hem duodenum biyopsisi bulunan olgularda $H$. pylori gastriti ile çölyak hastalığı arasındaki ilişki değerlendirilmiştir. Istatistiksel analizler Statistica Version 13.3 programı ile yapılmıştır. Sonuçlarda \%95 güven aralığında p< 0.05 olduğu durumlar istatistiksel olarak anlamlı kabul edilmiştir.

Bu çalışma, Mersin Üniversitesi Klinik Araştırmalar Etik Kurulu'nda 22.02.2018 tarihinde 2018/93 no'lu kararı ile onay almiştır

\section{BULGULAR}

Çalışmamıza mide ve/veya duodenum biyopsisi bulunan 18 yaş altı toplam 494 olgu dahil edilmiştir. 43 olguda sadece mide biyopsisi, 12 olguda sadece duodenum biyopsisi bulunmaktaydı, 439 olguda ise hem mide hem duodenum biyopsisi incelenmiştir.

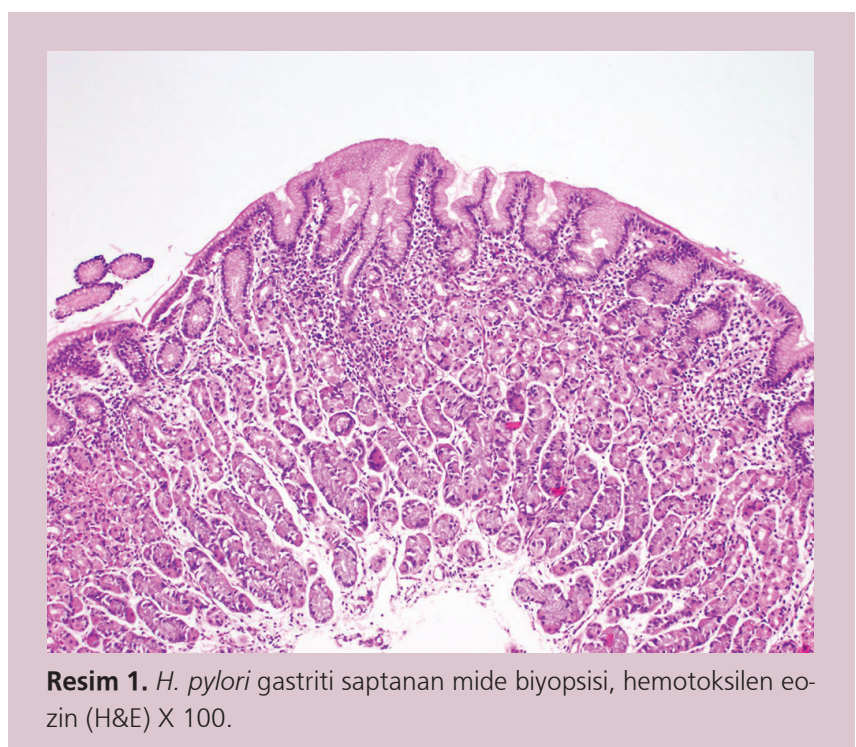

Mide biyopsisi bulunan 482 olgunun 162'sinde (\%33.6) H. pylori gastriti saptanmıştır (Resim 1,2). H. pylori pozitif 162 olgunun 18'inde sadece mide biyopsisi mevcut olup, duodenum değerlendirilememiştir. Toplam 451 duodenum biyopsisi bulunan olguların 37'sinde (\%8.2) çölyak hastalığı tespit edilmiştir. 37 çölyak olgusunun ise 4'ünde mide biyopsisi bulunmadığı için değerlendirilememiştir.

Hem mide hem duodenum biyopsisi bulunan 439 olgu ayrica incelendiğinde ise 144 olguda $H$. pylori gastriti, 33 olguda çölyak hastalığı bulunduğu saptanmıştır. Çölyak hastalığı tanısı alan 33 olgudan 1 l'inde (\%33.3) H. pylori gastriti saptanmış, 22'sinde H. pylori tespit edilememiştir. Çölyak hastalığı tanısı alan 4 olguda ise mide biyopsisi bulunmadığından değerlendirilememiştir (Tablo 1).

Duodenum biyopsisi bulunan ve H. pylori gastriti tanısı almış 144 olgunun ise 1l'inde (\%7.6) çölyak hastalığı tespit edilmiştir (Resim 3,4). İstatistiksel olarak H. pylori gastriti olan ve olmayan olgularda çölyak hastalığı görülme sıklığı açısından anlamlı bir ilişki saptanmamıştır $(p=0,543)$. Benzer şekilde çölyak hastalığı saptanan ile çölyak hastalığı bulunmayan olgular karşılaştırıldığında H. pylori gastritinin görülme sıklığı açısından istatistiksel olarak anlamlı bir farklılık tespit edilmemiştir ( $\mathrm{p}=0.529)$

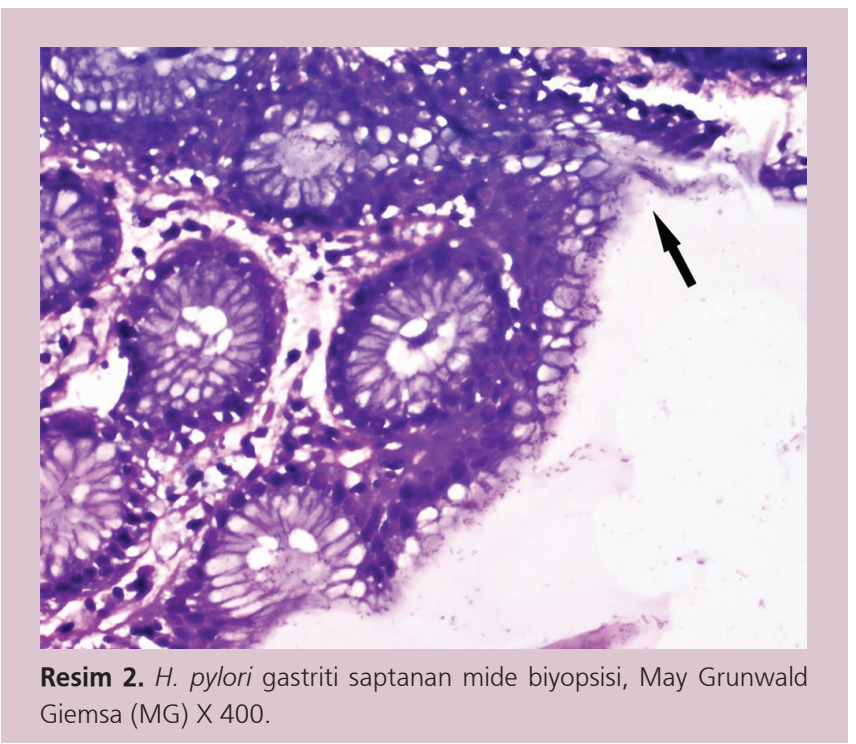

Tablo 1. Çölyak hastalığı ve H. pylori gastrit sıklığı arasındaki ilişki

Çölyak Hastalığı Mevcut (n=33)

H. pylori gastriti mevcut $(\mathrm{n}=144)$

H. pylori gastriti yok $(\mathrm{n}=295)$ 


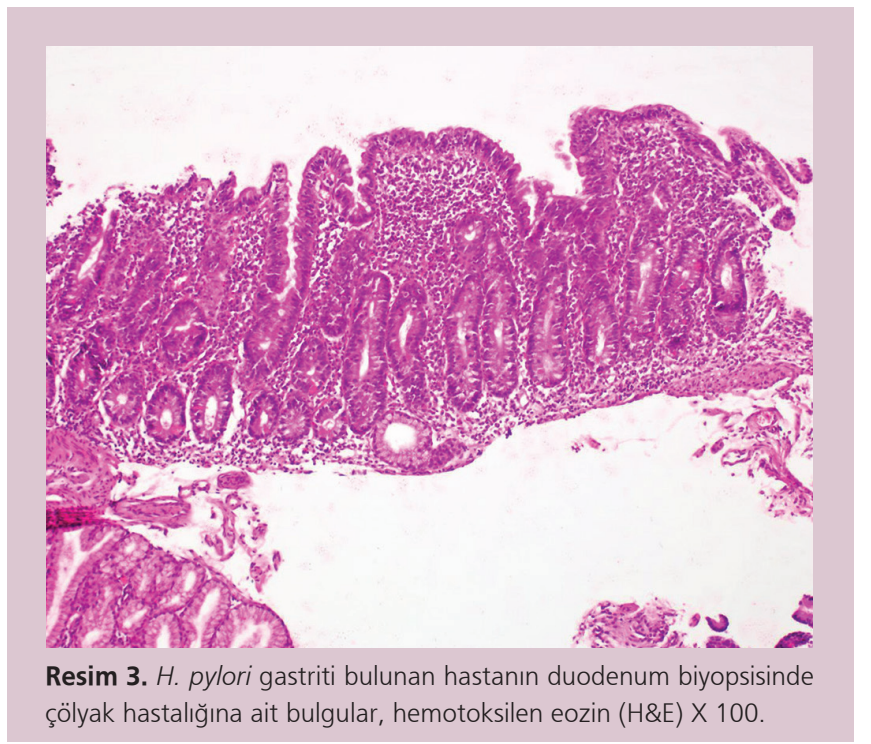

\section{TARTIŞMA}

H. pylori kronik gastrit, duodenal ülser ve adenokarsinom dahil olmak üzere önemli gastroduodenal hastalıklara neden olabilen bir bakteridir (9). Çeșitli otoimmün hastalıklarla ilişkilendirilen nadir enfeksiyöz ajanlardan biridir (10). H. pylori enfeksiyonu ince barsakta inflamatuvar ve immün cevabı etkileyebilir. Genetik yatkınlığı bulunan kişilerde gluten ile ilişkili enteropatinin gelișmesine neden olabilir $(11,12)$. Hem H. pylori enfeksiyonunda hem de çölyak hastalığında doğal immün inflamatuvar yanıt izlenmesine rağmen, sistemik humoral immün reaksiyon da saptanabilmektedir (13).

Çölyak hastalığı prevalansının Batı popülasyonunda \%0.8-1 olduğu tahmin edilmektedir (14). Bizim toplumumuzda ise bu oran yaklaşı \% 0.5 olarak bildirilmiștir (15). H. pylori gastriti ile çölyak hastalığı arasındaki ilişkiyi araştıran çeşitli çalışmalar yapılmış fakat çelişkili sonuçlar elde edilmiştir (68). Az sayıdaki çalışma H. pylori gastriti ve çölyak hastalığı ilişkisini desteklemektedir, fakat çoğu çalışmada bizim çalışmamıza benzer şekilde ilişki saptanmamıştır. Bazı çalışmalar duodenal mukozadaki intraepitelyal lenfositlerin sayısının $H$. pylori gastriti olan hastalarda daha yüksek olduğunu saptamış ve epidemiyolojik çalışmaların gastrit ve çölyak hastalığı arasındaki ilişkiyi göstermede başarısız olmasına rağmen, $H$. pylori’nin yok edilmesiyle çölyak hastalı̆̆ının kontrol altına alınabileceğini iddia etmiştir (8-16).

Çölyak hastalığındaki en erken duodenal histopatolojik bulgulardan biri intraepitelyal lenfositlerdeki artıştır. Bu bulgu, herhangi bir klinik veya serolojik çölyak hastalığı kanıtı olmaksızın H. pylori gastritli hastaların \%40'ında da gözlemlenmisstir ve intraepitelyal lenfositozun $H$. pylori'nin ortadan kaldırılmasıyla tersine çevrilebildiği saptanmıştır (16).

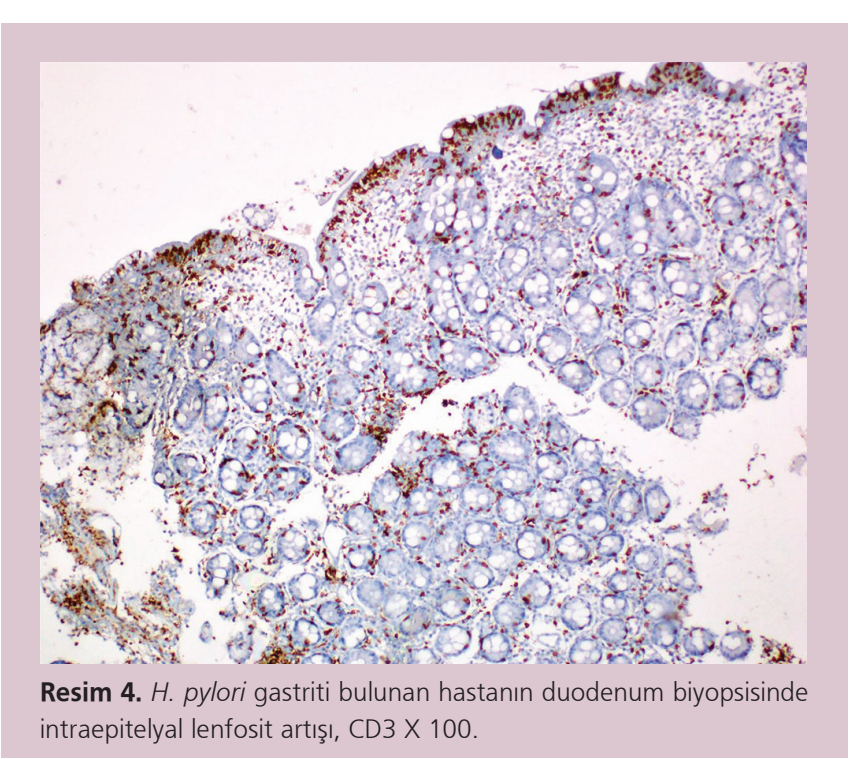

Crabtree ve ark. çölyak hastalığı olan ve olmayan hastalar arasında H. pylori prevalansını incelemiş ve aralarında bir farklılık bulunmadığını saptamışlardır (17). Luzza ve arkadaşlarının çalışmasında da çölyak hastalığı bulunan 81 çocuk ile çölyak hastası olmayan 81 çocuk incelenmiş, çölyak hastalarının $\% 18.5$ 'inde, diğer grubun \%17,3'ünde H. pylori enfeksiyonu olduğunu tespit etmişlerdir. Çölyak hastalığı bulunan çocuklarda H. pylori enfeksiyonunun prevalansının artmadığını iddia etmişlerdir (18). Diamanti ve ark. ise çölyak hastalarında H. pylori enfeksiyonu prevalansının kontrollere kiyasla anlamlı olarak daha düşük olduğunu tespit etmişlerdir (19). Rostami Nejad ve arkadaşları da benzer sonuçlar bulmuşlardır (20).

Bir başka çalışmada ise incelenen 312 olgunun 72'sinde çölyak hastalığı tespit edilmiş, çölyak hastalarında $H$. pylori enfeksiyon prevalansının \%12.5, çölyak hastalığı olmayanlarda prevalansın \%30 olduğu saptanmıştır (21). Böylelikle yazarlar çölyak hastalığı olmayan kişilerde $H$. pylori enfeksiyonu prevalansının daha fazla olduğunu vurgulamışlardır. Yine aynı çalışmada literatür ile karşılaştırıldığında çelişkili veriler olduğu belirtilmiş ve H. pylori enfeksiyonunun çölyak hastalığı için koruyucu nitelikte olabileceği de tartışılmıştır. H. pylori tarafından aktive edilen T regülatör lenfositlerin sistemik etkileri vardır. T regülatör lenfositler çölyak hastalığının patogenezinde de rol oynayabilir, çünkü bağırsak duvarındaki T regülatör lenfositlerin aracılık ettiği hücresel yanıtın baskılanması çölyak hastalarında azalmaktadır $(22,23)$. Ek olarak, H. pylori, gastrik pH'yı değiştirerek veya proteazları ile etkileyerek sindirilmiş glutenin immünojenitesini azaltabilir (24). Bu durum H. pylori enfeksiyonunun çölyak hastalığı için koruyucu olabilme iddiasını desteklemektedir. Bizim çalışmamızda ise çölyak hastalarında H. pylori gastritinin sıklığı \%33.3, çölyak hastalığı bulunmayanlarda \%32,7 olarak tespit edilmiștir ve aralarında anlamlı fark bulunmamıștır. 
Literatürdeki çalışmaların birçoğu birlikte değerlendirildiğinde, olgu sayıları da göz önüne alındığında normal popülasyondaki $H$. pylori gastriti sıklığının çölyak hastalarındaki $H$. pylori gastriti sıklığı ile benzer olduğu belirlenmiştir. Bizim çalışmamızda da anlamlı bir fark görülmemiştir. Bu sonuç literatür ile uyumlu olarak yorumlanabilir ancak normal popülasyonda ve çölyak hastalığı olan bireylerde H. pylori sıklığında anlamlı bir fark bulunmamasının başka nedenleri de olabilir. Bunun nedeni örneklemimizde mevcut olan hastaların aslında tam olarak normal popülasyonu temsil etmediği, bir çoğunun dispeptik șikayetler ile kliniğe başvurmuş olduğu bilinmektedir. Yine bu hastaların birçoğunda da endoskopik olarak H. pylori gastritini düşündürecek bulgular mevcuttur. Dolayısıyla dispeptik şikayetler ile gelen hastalardan alınan biyopsilerde görülen $H$. pylori gastriti sıklığı, normal popülasyondan fazla olabilecektir ve çölyak hastalığı tanısı sorgulanan olgularda görülen H. pylori gastriti sıklı̆̆ı ile benzer sonuçlar elde edilmiş olabilir. Kronik ishal, steatore, kilo kaybı gibi agresif bulgular ile seyreden çölyak hastalığı araştırılan olgularda endoskopik incelemede midede mevcut olan olası H. pylori gastritinin ön tanılarda bulunmama ihtimali ile histopatolojik incelemelerde de çölyak hastalığına odaklanılması ve bazı vakalarda H. pylori gastritinin atlanmış olabileceği ve böylelikle

\section{KAYNAKLAR}

1. Green PH, Cellier C. Celiac disease. N Engl J Med 2007;357:1731-43.

2. Ertekin V, Selimoglu MA, Doneray H, Orbak Z, Ozkan B. Prevalence of celiac disease in a sample of Turkish children and adolescents with type 1 diabetes mellitus. J Clin Gastroenterol 2006;40:655-7.

3. Oberthuber G, Granditsch G, Vogelsang H. The histopathology of coeliac diease: time for a standardized report scheme for pathologists. Eur J Gastroenterol Hepatol 1999;11:1185-94.

4. Smyk DS, Koutsoumpas AL, Mytilinaiou MG, et al. Helicobacter pylori and autoimmune disease: cause or by stander. World J Gastroenterol 2014;20:613-29.

5. Veres G, Pehlivanoglu E. Helicobacter pylori infection in pediatrics. Helicobacter 2007;12:38-44

6. Villanacci V, Bassotti G, Liserre B, et al. Helicobacter pylori infection in patients with celiac disease. Am J Gastroenterol 2006;101:1880-5

7. Konturek PC, Karczewska E, Dieterich W, Hahn EG, Schuppan D. Increased prevalence of Helicobacter pylori infection in patients with celiac disease. Am J Gastroenterol 2000;95:3682-3.

8. Ciacci C, Squillante A, Rendina D et al. Helicobacter pylori infection and peptic disease in coeliac disease. Eur J Gastroenterol Hepatol 2000;12:1283-7.

9. Garza-González E, Perez-Perez GI, Maldonado-Garza HJ, Bosques-Padilla FJ. A review of Helicobacter pylori diagnosis, treatment, and methods to detect eradication. World J Gastroenterol 2014;20:1438-49.

10. Smyk DS, Koutsoumpas AL, Mytilinaiou MG, et al. Helicobacter pylori and autoimmune disease: cause or by stander. World J Gastroenterol 2014;20:613-29.

11. Somech R, Spirer Z. Celiac disease: extraintestinal manifestations, associated diseases and complications. Adv Pediatr 2002;49:191-201.

12. Rewers M. Epidemiology of celiac disease: what are the prevalence, incidence, and progressions of celiac disease? Gastroenterology 2005;128(Suppl 1):S47-51

13. Broide E, Sandbank J, Scapa E, et al. The immunohistochemistery profile of lymphocytic gatritis in celiac disease and helicobacter pylori infection: interplay between infection and inflammation. Mediators Inflamm 2007;2007:81838. çölyak hastalığı bulunan olgularda H. pylori gastriti sıklığının gerçeği yansıtmaması nedenlerden bir başkası olabilir.

Ülkemizde yapılan bir çalışmada Artvin bölgesinde, dispeptik şikayetleri bulunan hastaların endoskopik biyopsilerinin incelenmesi sonucunda \%5'inde çölyak hastalığı tespit edilirken, H. pylori gastritli hastaların ise \%3.6'sında çölyak hastalığı görülmüştür (25). Bu oran bizim çalışmamızda \%7.6'dır. Bizde bu oranın daha yüksek olma nedeni, çölyak hastalığının patogenezinde var olduğu bilinen, yöresel farklılıklar, beslenme alışkanlıkları, enfeksiyöz ajanlara maruziyet sıklığı gibi birtakım çevresel risk faktörlerinin ince barsak otoimmünitesi üzerine olan etkisi ile ilişkili olabilir. Ancak ülkemizde, H. pylori gastriti olan hastalarda eşlik eden çölyak hastalığı sıklığına dair yeterli sayıda çalışma yoktur. Araştırmamız sonucunda, objektif bir gözle değerlendirildiğinde her olgunun kliniğe yansıyan en önemli semptomlarını açılayan mevcut hastalığı yanı sıra farklı bir lokalizasyonda ikinci bir hastalığı da barındırabileceği ve her olgunun endoskopik ve histopatolojik olarak bu gözle değerlendirilmesini önermekteyiz. Mevcut çalışmalar ile ilgili literatürde farklı veriler, farklı yorumlar sunulmuş olup, olası ilişkinin saptanması için daha geniş vaka sayılı çalışmalar literatüre ışık tutacaktır.

14. Abu Daya H, Lebwohl B, Lewis SK, Green PH. Celiac disease patients presenting with anemia have more severe disease than those presenting with diarrhe. Clin Gastroenterol Hepatol 2013;11:1472-7.

15. Dalgic B, Sari S, Basturk B, et al. Prevalence of celiac disease in healthy Turkish school children. Am J Gastroenterology 2011;106:1512-7.

16. Memeo L, Jhang j, Hibshoosh H, et al. Duodenal intraepithelial lymphocytosis with normal villous architecture: Common occurrence in Helicobacter pylori gastritis. Mod Pathol 2005;18:1134-44.

17. Crabtree JE, O'Mahony S, Wyatt JI, et al. Helicobacter pylori serology in patients with coeliac disease and dermatitis herpetiformis. J Clin Pathol 1992;45:597-600.

18. Luzza F, Mancuso M, Imeneo M, et al. Helicobacter infection in children with celiac diease: prevalence and clinicopathologic features. J Ped Gastroenterol Nutr 1999;28:143-6.

19. Diamanti A, Maino C, Niveloni S, et al. Characterization of gastric mucosal lesions in patients with Celiac disease: a prospective controlled study. Am J Gastroenterol 1999;94:1313-9.

20. Rostami-Nejad M, Villanacci V, Mashayakhi R, et al. Celiac disease and Hp infection association in Iran. Rev Esp Enferm Dig 2009;101:850-4.

21. Lasa J, Zubiaurre I, Dima G, Peralta D, Soifer L. Helicobacter pylori prevalence in patient with celiac diease: reults from a cross-sectional study. Arq Gatroenterol 2015;52:139-42.

22. Lebwohl B, Blaser MJ, Ludvigsson JF, et al. Decreased risk of celiac disease in patients with Helicobacter pylori colonization. Am J Epidemiol 2013;178:1721-30.

23. Arnold IC, Dehzad N, Reuter S, et al. Helicobacter pylori infection prevents allergic asthma in mouse models through the induction of regulatory T cells. J Clin Invest 2011;121:3088-93

24. Chen Y, Segers S, Blaser MJ. Association between Helicobacter pylori and mortality in the NHANES III study. Gut 2013;62:1262-9.

25. Basyigit S, Unsal O, Uzman M, et al. Relationship between Helicobacter pylori infection and celiac disease: a crosssectional study and a brief review of the literature. Prz Gastroenterol 2017;12:49-54. 